\title{
Seguimento psicológico para agressores domésticos de crianças: protocolo de atendimento psicoterápico breve
}

\author{
Follow-up counseling for aggressors of domestic children: \\ brief psychotherapy protocol \\ Tratamiento psicológico de agresores domésticos de niños: \\ protocolo de psicoterapia breve
}

Artenira da Silva e Silva Sauaia ${ }^{1 \star}$, Maurilene de Andrade Lima Bacelar de Arruda², Jonhnny Welton Feitosa Melo³

Palavras-chave: Violência doméstica

Infância

Psicoterapia Maus-Tratos Infantis Pré-Escolar
Keywords: Domestic violence Childhood

Psychotherapy

Child Abuse

Child, Preschool

\section{Resumo}

Pessoas que sofreram violência doméstica na primeira infância carregam sequelas emocionais, que se perpetuam em diferentes níveis. Isso representa um alto risco de repetição, quer no âmbito familiar, quer servindo de mola propulsora para a violência social, perpetuando-se um ciclo de violência que constitui uma epidemia no Brasil. Em especial porque na primeira infância ocorre a construção da autoestima e da visão de mundo, a partir das sensações experimentadas e das relações vivenciadas. Propor e reforçar a importância de um tratamento psicoterápico para o agressor doméstico de crianças trata-se de uma ação pioneira no Brasil, e constitui o objetivo do presente trabalho. Foram acompanhados 98 agressores em núcleo específico para esse fim. 0 recrutamento se deu por demanda espontânea e contou com uma rede social de apoio para divulgação na comunidade. 0 estudo revelou que tratar 0 agressor é uma alternativa viável e muito eficiente no que tange a proteger a própria vítima. Por meio dessa intervenção, objetiva-se contribuir para tentar interromper de forma eficaz o ciclo de repetição de violência que muitas famílias carregam.

\section{Abstract}

People who have experienced domestic violence in their early infancy retain negative emotional experiences that continue to influence their lives in different levels. This may represent a high risk of violence repetition, either within the family environment or catalyzing social violence, perpetuating a cycle of violence that is epidemic in Brazil. This happens mainly because at that age, from zero to six years of age, the child is building up his or her self-esteem as well as their view of the outside world, based upon the sensations experienced and upon their personal relations. Proposing and enhancing a psychotherapeutic treatment for the offender as a more positive approach in fighting domestic violence against children is a pioneer effort in Brazil and was the goal of this study. Ninety-eight aggressors were followed-up in the core for this specific purpose. Recruitment took place spontaneously and had a community outreach social support network. The study showed that treating the offender is a viable alternative to benefit the victim more effectively than only treating the victim him/herself, as well as involving the victim in the aggressor's treatment. This intervention aims at contributing to effectively try to stop the repetitive cycle of violence that many families go through.

'Universidade Federal do Maranhão (UFMA). artenirassilva@hotmail.com

${ }^{2}$ Grupo de Pesquisa em Saúde Mental da Universidade Federal do Maranhão (UFMA). maurilenebacelar@yahoo.com.br

${ }^{3}$ Grupo de Pesquisa em Saúde Mental da Universidade Federal do Maranhão (UFMA). jwfmelo@hotmail.com

*Autor correspondente.

Fonte de financiamento: Serviço Social do Comércio (SESC) e Fundo das Nações Unidas para a Infância (Unicef).

Conflito de interesses: declararam não haver.

Recebido em: 20/06/2011

Aprovado em: 17/01/2012 


\begin{abstract}
Palabras clave: Resumen
Violencia doméstica

Infancia

Psicoterapia

Maltrato a los Niños

Preescolar

Las personas que sufren la violencia doméstica en la primera infancia llevan secuelas emocionales que se perpetúan en los diferentes niveles. Esto representa un alto riesgo de repetición, sea en la familia sea sirviendo como catalizador de la violencia social, perpetuando un ciclo de violencia, que constituye una epidemia en Brasil. En particular, porque la primera infancia es la construcción de la autoestima y de la visión del mundo, a partir de las sensaciones experimentadas y de las relaciones vividas. Proponer y reforzar la importancia de un tratamiento psicoterapéutico para el agresor de niños es un esfuerzo pionero en Brasil y constituyó el objetivo del estudio. Noventa y ocho agresores fueron seguidos en el centro para este propósito específico. El reclutamiento se llevó por la búsqueda espontánea y tenía una red de apoyo social para convencer la comunidad. Esto estudio reveló que el tratamiento del agresor es una alternativa viable y muy eficiente cuando se trata de proteger a la víctima. Esta intervención tiene como objetivo contribuir de forma efectiva para detener el ciclo de repetición de la violencia que muchas familias llevan.
\end{abstract}

\section{Introdução}

Ultrapassou-se o tempo em que bater em uma criança era considerado uma maneira de educar. Esta problemática tem sido alvo de constantes discussões, enriquecidas com a produção de diversos estudos e de outras contribuições científicas e jurídicas, como o Estatuto da Criança e do Adolescente (ECA). Tais construções visam suplantar a pré-noção deixada pelo senso comum de que agredir a criança poderá ser uma abordagem educacional. Surpreendentemente, mesmo nos ambientes intelectuais, essa ideologia ainda é bastante arraigada e a violência doméstica contra a criança constitui-se prática comum e problemática social grave ${ }^{1,2}$.

Esse tipo de violência é regida pelo artigo quinto do ECA, que menciona: "nenhuma criança ou adolescente será objeto de qualquer forma de negligência, discriminação, exploração, violência, crueldade e opressão, punido na forma da lei qualquer atentado, por ação ou omissão, aos seus direitos fundamentais".

A discussão foi ampliada, inicialmente, com a classificação de agressões à criança no simpósio da academia americana de Pediatria, em 1949. Tais agressões foram divididas em: violência física realizada de forma direta (socos, pontapés, palmadas etc.) ou indireta (com instrumentos de castigo); abandono físico ou moral com o não-provimento dos cuidados básicos, como alimentação e higiene (abandono físico); e o não-provimento de um lar (abandono moral), deixando a criança exposta a alguns perigos, como vícios e más companhias, abuso sexual (agressão sexual por um adulto), exploração sexual e maus-tratos psicológicos como insultos, agressão verbal e intimidação. Essas formas produzem sérios traumas na vida do infante ${ }^{3}$. A criança que se encontra na primeira infância, fase que ocorre de zero a seis anos, apresenta alguns fatores agravantes no que se refere às consequências danosas de ter sofrido violência em seu ambiente doméstico, a saber: dependência emocional acentuada ou maior fragilidade em relação aos outros membros da família.

O fato de ser agredida por quem deveria protegê-la, sendo o agressor também cuidador (termo utilizado para carac- terizar os responsáveis pela criança), contribui para que se esteja diante de uma ambiguidade da relação que é emocionalmente desestruturante para o infante $e^{4}$. A criança tem de lidar com um conflito enorme, que é o de amar o agressor e odiar a agressão ${ }^{5}$, chegando, por isso, a mentir para proteger o agressor. Mesmo odiando a agressão, a criança apresenta-se em conflito, o que confere segurança para que o agressor possa perpetuar o ciclo de agressões sem uma preocupação maior em ser denunciado e/ou judicialmente punido.

No entanto, apesar de ser um fenômeno que ocorre desde a antiguidade, a violência doméstica, em especial a que é direcionada contra crianças e adolescentes, passou a ser mais amplamente discutida apenas a partir da década de 1980, época em que começaram a surgir os primeiros programas para atendimentos relacionados ao tema ${ }^{6}$.

O presente estudo visou o atendimento psicoterápico do agressor doméstico de crianças na primeira infância. Este é o período no qual o ser humano adquire um sentimento de segurança ou insegurança em relação ao mundo, bem como sedimenta ou não sua autoestima, o que terá uma influência marcante no futuro desenvolvimento pessoal, relacional, social e profissional ${ }^{6}$. É a fase em que pode-se começar a introjeção de regras de convivência cidadã. Além disso, a criança começa a adquirir resistência a frustrações futuras, bem como o hábito de gostar de estudar, o que poderá ser determinante para a ampliação de suas oportunidades e para sua futura inserção no mercado de trabalho ${ }^{1}$.

Cumpre ressaltar que o estudo privilegiou o atendimento ao agressor da criança, por pressupor ser esta uma via mais ágil para tentar inibir a prática da violência. Isso porque o atendimento exclusivo à vítima não garante a interrupção da violência cometida pelo agressor, apesar de capacitar emocionalmente o violentado a ressignificar a violência sofrida, amenizando as sequelas deixadas no corpo e, principalmente, na 'alma' do agredido ${ }^{7}$.

Os serviços de atendimento a crianças vítimas de violência intrafamiliar, por vezes, incluem o atendimento psicossocial à família, mas focando sempre a vítima. $\mathrm{O}$ atendimento proposto e testado neste estudo foi o de cuidar das dores internas de cada 
agressor e de ajudá-lo a adquirir a percepção de responsabilização pela violência causada. O objetivo foi despertá-los para uma forma diferente de lidar com seus conflitos, dores ou temores internos. Olhar para suas frustrações ao invés de projetá-las nas crianças que o cercam em sua realidade externa, quer por elas serem alvos fáceis de depósito do estresse do adulto em função de serem mais indefesas, quer porque ele sente que a criança é propriedade dos adultos que a geraram ${ }^{4}$. Propõe-se, assim, mais uma alternativa que se mostrou eficiente no que tange a aumentar as chances de interromper ou cessar o ciclo ${ }^{8}$ grotesco da violência intrafamiliar contra a criança.

Ao traçar o perfil pioneiro de agressores diretos e indiretos (aqueles que sabem da existência da violência, mas nada fazem para interrompê-la e proteger a vítima), o estudo ousou aproximar-se dos violentadores para, de perto, sensibilizá-los, ajudando-os a desenvolver a percepção de responsabilização frente à violência causada, acolhendo e ressignificando seus conflitos internos. Acolher o mundo interno de cada agressor como estratégia psicoterápica visa contribuir para a redução da epidemia de violência intrafamiliar contra crianças, quadro que continua assolando o Brasil e aterrorizando os brasileiros com os dados alarmantes acerca dessa problemática ${ }^{1,2}$.

Devido ao fato desse tipo de agressão ser praticada essencialmente por supostos cuidadores (pais biológicos, parentes diretos ou amigos ligados à família), assume-se uma forma ainda mais grave que a própria violência social, pois tende a ser repetida, velada e delimitada por um ambiente comum ao agredido e ao agressor. Ambiente este que deveria conferir proteção ao infante, o que potencializa uma possível desestabilização emocional do agredido 5 . A criança submetida à violência doméstica em suas variadas formas, física, sexual, moral, psicológica, afetiva ou intelectual acaba por ser vítima de mais de uma ou várias dessas agressões simultânea e repetidamente, pois a violência psicológica, por exemplo, acompanha todas as outras.

Há, portanto, consequências mais perpetuadoras e futuramente devastadoras para as vítimas desse tipo de violência e até para a sociedade em geral, uma vez que é possível afirmar que a violência intrafamiliar pode ser uma das âncoras da violência social ${ }^{9}$.

Para a resolução do problema em questão, fazem-se necessárias medidas que consistam na implementação de políticas públicas que visem o tratamento ou acompanhamento psicológico dos agentes da agressão, além da implementação de políticas públicas que definam uma intervenção preventiva em saúde mental, articulando as diversas políticas de saúde atual com a profilaxia e atenção básica em saúde mental ${ }^{10}$.

É necessário capacitar as equipes de saúde da família com conhecimento transdisciplinar, a fim de que formas de aborda- gens necessárias sejam executadas, as quais visem à prevenção primária e secundária em relação à violência, como a identificação de crianças com maior risco para maus-tratos por meio das visitas de supervisão de rotina de saúde da criança com orientações preventivas. Como medida de prevenção terciária, pode-se evidenciar a possibilidade de identificação da violência ${ }^{10}$.

A Psicoterapia Psicodinâmica Breve foi uma ferramenta importante nesse processo. Constitui-se de intervenção terapêutica com tempo e objetivos bem delimitados, estabelecidos a partir da compreensão diagnóstica do paciente. Está segmentada em três modelos, o estrutural ou do impulso, o relacional e o eclético ou integrativo. Essa classificação foi desenvolvida por Messen e Warren, em 1995, no texto de Oliveira, que agrupam as várias abordagens de acordo com modelos teóricos e técnicos ${ }^{10}$. $\mathrm{Na}$ abordagem realizada pelo presente estudo, sobressaiu-se o modelo relacional, o qual se detém no reconhecimento do objeto de estudo de uma forma contextual, na qual é possível a pluralidade dos pontos de vista. Diferentemente dos outros modelos, o terapeuta não é tido como onipotente, não sendo importante somente a interpretação da realidade do paciente, mas possibilitando-se desenvolver, no curso psicoterápico, uma visão compartilhada e ressignificada da violência ${ }^{10}$.

Nesse modelo, a unidade básica de estudo não é o indivíduo como uma entidade isolada daqueles com quem se relaciona ou do seu ambiente, cujos desejos se chocam com a realidade externa, mas um campo relacional dentro do qual o indivíduo surge e luta para fazer contato e para se articular. Ao invés de propor abordagens técnicas específicas, este modelo prioriza a relação terapêutica e os padrões de relacionamento interpessoal que o indivíduo estabelece com o próprio terapeuta, como espelhamento de suas relações com aqueles com quem convive, servindo o terapeuta como um facilitador da percepção do paciente de si mesmo ${ }^{10}$.

Conforme discutido, o presente trabalho objetivou estudar o atendimento psicoterápico do agressor doméstico de crianças na primeira infância, e foi impulsionado pela ausência de registros anteriores na literatura a respeito de processos semelhantes. A eficiência da Psicoterapia Psicodinâmica Breve justifica sua experimentação no combate ao ciclo violento que se perpetua na sociedade.

\section{Material e métodos}

Antes de montar um protocolo de atendimento, realizou-se uma pesquisa de campo com metodologia qualitativa, utilizando-se entrevistas semiestruturadas e observações de campo, a partir de visitas domiciliares a famílias atendidas nos programas de Saúde de Família, em nove zonas distri- 
tais do município de São Luís do Maranhão: Centro, Coroadinho, Itaqui-Bacanga, Anil, Turu, Bequimão, Cidade Operária, São Francisco e Zona Rural. Foram visitados 1.100 lares cobertos por 80 Equipes de Saúde da Família nessas mesmas regiões.

A partir dos resultados, levantaram-se pressupostos tocantes à violência doméstica contra a criança na primeira infância, que orientaram a criação de um protocolo piloto de atendimento com temas pré-definidos pela equipe de 11 membros, por especializandos em Saúde Mental, pela coordenadora docente do projeto e por estudantes de graduação.

As questões relativas à detecção de modos de ajuda, capazes de diminuir a repetição da violência intrafamiliar, levantaram os seguintes pressupostos metodológicos:

Talvez os pais e a população em geral ainda achem que o que ocorre na esfera familiar é do âmbito do privado e, por isso, a criança lhes pertence.

- A necessidade de expressar o domínio sobre uma criança, agredindo-a, pode constituir a projeção de agressões sofridas pelo agressor no seu âmbito familiar original ou no decorrer de suas experiências relacionais, o que precisaria ser explorado para que tenha melhor possibilidade de lidar com seu passado e com as formas de relacionamento por ele desenvolvidas.

- É frequente a literatura associar episódios de agressão ao abuso do álcool ou ao consumo de outras drogas psicotrópicas, ensejando a necessidade de encaminhar o agressor e seus familiares a instituições como o Alcoólicos Anônimos (AA) e a Associação de Parentes e Amigos de Alcoólicos (ALANON) ou a algum serviço de psiquiatria.

- Uma atividade laboral insalubre e estressante, na qual o agressor se sinta desvalorizado e humilhado, também pode ensejar que ele libere sua frustração no ambiente doméstico.

- Conflitos pessoais do próprio agressor contribuem significativamente para que agrida a criança que a ele cabe amar e proteger, daí a absoluta necessidade de se criar um espaço específico para ajudar esse cidadão a lidar com suas dificuldades emocionais.

- A intervenção terapêutica foi realizada em 98 agressores, dos quais 87 permitiram a utilização dos dados para a pesquisa. $\mathrm{O}$ processo de psicoterapia psicodinâmica breve ocorreu em aproximadamente 15 sessões. Os sujeitos de pesquisa foram atendidos entre outubro de 2007 a junho de 2008. Durante os seis meses, o trabalho foi ininterrupto, incluindo fins de semana e feriados. Ocorreu até mesmo de dezembro e janeiro, em razão da sensibilização afetiva que, em geral, é provocada pelas festas comemorativas de final do ano, deixando as pessoas mais emotivas e voltadas para conflitos familiares e para suas frustrações em geral.
O local de atendimento foi denominado Centro de Resgate das Relações Familiares, não localizado nos bairros da pesquisa, onde já se prestava atendimento psicológico voluntário comunitário. Foi realizado um plano de atendimento de sondagem, no qual se identificou resistência do público alvo quanto ao local de atendimento inicialmente proposto, em função do mesmo ser ao lado de uma escola. Decidiu-se, por isso, escolher um segundo local para implementar a sala de atendimento que fosse geograficamente distante de escolas, delegacias, conselhos tutelares ou qualquer outra instituição capaz de criar outras resistências ou temor por parte dos agressores.

A divulgação do Centro foi realizada nas principais igrejas e escolas das referidas zonas distritais, por meio de cartões de visita e de uma apostila, que continha informações sensibilizadoras sobre a questão da violência doméstica. $\mathrm{O}$ cartão de visita continha apenas um telefone para o qual se poderia ligar a cobrar para agendar um atendimento. Após o contato, os usuários iniciavam o plano psicoterápico, sem obrigatoriedade de fornecer seus endereços ou quaisquer outras informações pessoais que não desejassem inicialmente.

Os atendimentos foram, prioritariamente, individuais, com duração de uma hora semanal, realizados pela equipe previamente descrita. Ocorreram, entretanto, atendimentos em grupo, com aproximadamente 15 participantes em cada sessão com duração média de duas horas cada, tendo como facilitadora das discussões e intervenções a coordenadora da pesquisa.

Seguiu-se a modalidade Psicoterapia Psicodinâmica Breve, com aproximadamente 15 sessões, num período de aproximadamente quatro meses, com duas sessões de follow-up: uma 15 dias após o término do atendimento e outra um mês após o processo de terapia breve realizado.

Os casos que foram identificados como apresentando psicopatologia que requeresse o uso de medicação psicotrópica e/ou qualquer outro tipo de intervenção medicamentosa foram diretamente encaminhados aos ambulatórios do Hospital Universitário da Universidade Federal do Maranhão (UFMA), ao Hospital Psiquiátrico Local (CAPS III) ou ao Hospital Nina Rodrigues para o acompanhamento médico.

Onze temas foram definidos para nortear as sessões individuais e as dinâmicas de terapia de grupo, formando o seguinte protocolo temático utilizado para nortear a terapia breve realizada com os agressores de violência doméstica contra a criança menor de seis anos de idade: Tema 1 - Como você se caracteriza como pessoa? Quais são suas principais qualidades e seus principais defeitos como marido, filho, pai, amigo, no geral?; Tema 2 - Caso você pudesse voltar o tempo o que mudaria na sua história de vida, da sua infância até hoje?; Tema 3 - Quais foram os melhores períodos da sua 
infância e adolescência?; Tema 4 -Como foi e como é hoje a sua relação com sua família de origem: pais, mãe, irmãos, tios, primos e outros?; Tema 5 - Como você constituiu sua família atual? Quais são os melhores momentos que vocês têm juntos?; Tema 6 - O que é família para você? Quais os principais direitos e deveres que cada membro da família precisa exercitar uns em relação ao outros?; Tema $8-\mathrm{O}$ que é violência? Qual a importância amorosa que seu filho/filha mantém para você?; Tema 9 - Você trabalha? Como você se sente no seu trabalho?; Tema 10 - Como você percebe seu papel na família que você tem hoje? e Tema 11 - Quais seus planos para os próximos seis meses ou um ano de sua vida?.

Os conceitos de família, identidade, cidadania, amor, paternidade e maternidade responsável foram abordados para suscitar sua ressignificação nas sessões individuais e de grupo, favorecendo a percepção de responsabilização do agressor em relação à violência cometida. Foram utilizados desenhos, fotos da família de origem e daquela constituída e a técnica de grupos focais, quando necessários.

Vale ressaltar que o projeto de pesquisa em questão foi aprovado pelo Conselho de Ética em Pesquisa com seres humanos da UFMA pelo parecer 433/07.

\section{Resultados}

As seguintes questões intrigavam a equipe: Como conduzir os agressores ao tratamento espontaneamente? Como fazê-los perceberem a necessidade de procurar ajuda? A participação de uma rede comunitária de apoio foi um meio bem-sucedido. Igrejas e Escolas assumiram um importante papel neste estudo como veículos de disseminação ideológica contra a violência doméstica e de apoio e incentivo à procura do tratamento. Essa abordagem inicial chamou-se de sensibilização.

A proposta alcançou seus objetivos. Tanto agressores diretos (que causam a agressão) quanto indiretos (que presenciam a agressão e se omitem) procuraram ajuda espontaneamente. Em alguns casos, o agressor indireto foi sensibilizado primeiramente e participou do processo de conscientização do agressor direto.

Assim, o seguimento psicoterápico do agressor foi identificado como a fase de acolhimento da abordagem proposta, uma vez que eles, livres de julgamento, puderam desenvolver confiança no processo terapêutico e assim ressignificar emoções atreladas à prática da violência. Para esse manejo, a equipe recebeu preparação adequada.

A maioria dos agressores não mantinha contato com suas famílias de origem ou relatava ter sofrido violência intrafamiliar ou social na sua vida pregressa. Os agressores expres- saram sentimento de inutilidade e insatisfação no emprego. Um total de $76 \%$ mudaria de emprego, caso tivesse a oportunidade e $35 \%$ encontravam-se desempregados.

A renda familiar dos agressores atendidos era, em média, um salário mínimo e meio, e o número de pessoas por casa era de quatro, sendo que $88 \%$ deles viviam de aluguel.

Quanto ao sentimento de posse, os agressores consideravam a criança um bem ou propriedade e a família como um espaço privado, na qual ninguém pode interferir. A relação com o trabalho e o nível de frustração que apresentavam acerca da mudança do quadro social era muito negativa. Seguem algumas falas iniciais dos agressores, coletadas nas três primeiras sessões:

Não dá pra ralar o dia todo, aguentando bumilhação, $e$ chegar em casa com menino aperriando. Não sou de ferro (33 anos).

Já criei oito filhos e 'gora' ficar correndo atrás de neto não dá. Ajudo minha filha e fico com ele, mas quando ele está muito atentado eu amarro ele na cama e bato com uma toalha molhada nos pés, para minha filha não ter mais aborrecimento e ver alguma 'rouxura' nele (69 anos).

É meu filho, então eu decido como educar (34 anos).

Se ela é minha filha e um dia ela vai dar para alguém por que eu não posso usufruir dela também? (47 anos).

Ela gosta. Não sei porque esse estardalhaço todo (24 anos). Confesso que chego cansada e não consigo ouvir o choro de bebê, me descontrolo e bato mesmo (23 anos).

A gente não pode deixar de ajudar mamãe. Ela trabalba muito e se deita com homens de noite. Eu e minha irmã ganbamos 50 reais por mês para chupar o pau de uma galera que contrata a gente aqui na vila, mas mamãe não sabe (6 anos).

Sei que meu marido abusa da minha filha. Tento evitar, já denunciei uma vez, não deu em nada, e ele voltou. Gosto dele e o dinheiro que ele bota em casa faz falta (45 anos).

Não adianta denunciar meu pai porque vou negar e já fugi três vezes de inventarem de me tirar de casa. Minha mãe largou ele, tenho ódio dela, e tem dois anos que não sei nem do paradeiro ela. Tenho uma irmã de sete e outra de quatro que se ele tocar nelas eu mato ele. Comigo tudo bem, já aceitei meu sacrifício, mas elas não (15 anos, grávida pela terceira vez do pai biológico e comete violência física contra os dois filhos que tem com o pai).

A partir dos encontros individuais e em grupo, os indivíduos conseguiram dar voz às suas frustrações mais dolorosas e expressá-las de modo verbal, bem como aos paradigmas relacionados à família e ao seu conteúdo simbólico. Essa é a fase da ressignificação, ou resposta positiva, objetivo máximo do processo. Criado o vínculo de 
confiança adequado, os possíveis facilitadores da violência puderam ser identificados e seu conteúdo ressignificado pelo agressor e, em alguns casos, por toda a família nos encontros conjuntos.

Como conclusão do tratamento Psicoterápico Breve escolhido, levando-se em conta a demanda e as condições dos pacientes e a disponibilidade da equipe, a resposta positiva, fase final de avaliação, em geral, foi satisfatória. Ao final, 22\% dos pacientes resolveram ir até a Delegacia de Proteção da Criança e do Adolescente para confessar a violência perante a qual estavam se omitindo, uma vez que não conseguiram sensibilizar o agressor direto. $20 \%$ dos agressores diretos buscaram ajuda por causa de denúncia ao mesmo órgão. Apesar da disponibilidade ao tratamento, $15 \%$ deles apenas aceitaram ser atendidos nos consultórios particulares dos membros da equipe. Assim, enfatiza-se que o atendimento ao agressor deve ser implantado em locais que não identifiquem o paciente atendido como um agressor e, assim, poder ser alvo de hostilidade social na comunidade na qual o local de atendimento está inserido.

Nas duas sessões de verificação (follow-up), foi obtido 91\% de retornos positivos em relação à agressão cometida, assumida ou denunciada. Todos aceitaram continuar a terapia por mais seis meses nos consultórios particulares da equipe. $30 \%$ dos atendimentos foram concluídos, possibilitando que os dois últimos ocorressem em conjunto com a vítima. Os dois atendimentos mensais de verificação, com 90\% dos agressores, foram realizados em dois momentos, individualmente e em conjunto com um membro familiar, em $10 \%$ dos casos, com a própria vítima. É importante destacar que os $10 \%$ que não retornaram espontaneamente para os atendimentos de verificação estavam dentro dos $20 \%$ já denunciados na Delegacia de Proteção à Criança e ao Adolescente, antes do início do atendimento psicológico.

\section{Discussão}

O trabalho foi bem-sucedido quanto à divulgação e percebeu-se que a demanda espontânea pelo serviço oferecido foi intensa, o que torna viável atender o agressor como uma estratégia importante no combate à violência intrafamiliar contra a criança. O paciente poderia opinar quanto ao local de atendimento e ficou livre para fornecer, ou não, seu endereço inicialmente.

Pioneiramente, o presente estudo definiu os traços comuns aos agressores desse tipo de violência, para, de posse desse conhecimento, propor um tratamento que permeasse as seguintes etapas: sensibilização, acolhimento e resposta positiva do agressor em relação à vitima.
Esse modelo de tratamento da violência doméstica mostrou-se eficaz como uma medida importante, no que se refere a contribuir em favor da interrupção do ciclo de violência focado neste estudo. Tratando a criança, é possível amenizar as consequências da violência para a vítima, mas não interrompe de fato o ciclo violento, pois este se origina do outro sujeito envolvido no ato.

A verbalização da violência sofrida e das insatisfações consequentes pelo agressor canalizou positivamente a resposta desejada pelo próprio paciente como expressão de sua própria dor. O silêncio da violência, ao contrário, impede o manejo das suas consequências psicológicas, imprimindo-lhe mais força e poder de construções inconscientes expressas em atitudes gradativamente mais repetitivas e intensas ${ }^{11}$.

Os primeiros temas trabalhados em terapia, de acordo com o protocolo temático, ressaltaram as relações afetivas do agressor e seus papéis sociais, objetivando a continuidade do processo de sensibilização iniciado na primeira etapa de contato com a comunidade, bem como favoreceram o enfrentamento do agressor de suas próprias dores. Considerou-se o acolhimento ao violentador uma ferramenta fundamental para a obtenção de bons resultados terapêuticos.

Quanto à vontade, 90\% dos pacientes gostariam de poder ter dado continuidade ao atendimento psicológico iniciado. As discussões sobre as relações de trabalho, sobre o significado de família e as necessidades de afeto e cuidado mostraram-se eficazes para trazer à tona o sentimento de culpa do agressor, relacionando a violência cometida aos outros aspectos da vida dele.

A prevenção nesse campo de saber pode favorecer a convivência cidadã, tornando as pessoas mais resilientes às frustrações da vida e diminuindo as chances delas fazerem uso da violência como mecanismo de interação interpessoal para lidar com seus conflitos internos. O combate a esse tipo de crime deve ser articulado às políticas públicas implementadas nos campos da educação, saúde e segurança pública, privilegiando as medidas profiláticas em saúde mental.

$O$ investimento na primeira infância importa como meio de diminuir a perpetuação da miséria e da violência social, tendo em vista que as agressões sofridas na infância são introjetas mais facilmente pela vítima, e sua simbologia adquire forma de verdade para o indivíduo, que perpetuará seu conteúdo de algum modo 8 .

\section{Conclusões}

Com este estudo, foi possível constatar que o procedimento proposto foi bem aceito pela população-alvo e se mostrou como uma possibilidade real de contribuir para a redução da 
violência contra a criança. Além do atendimento à vítima, aos familiares e aos violentadores, destaca-se a necessidade de capacitarem-se os educadores do Ensino Fundamental, bem como as Equipes de Saúde da Família e os membros de conselhos tutelares quanto a essa temática, a fim de que se possa formar redes de multiplicadores sobre o tema.

Programas locais devem atuar sinergicamente com campanhas de alcance nacional, as quais conscientizem a família do seu papel de educadoras e protetoras da criança, a fim de fixar a noção de que o ambiente familiar não pode continuar sendo tratado como privado, impenetrável ou inviolável, tendo em vista que a omissão da denúncia configura a agressão indireta.

O processo terapêutico revela-se duplamente útil, pois, ao mesmo tempo em que intervém de maneira ampla, individual e singular, curando as dores emocionais de agressores e agredidos, atua impedindo a reprodução comportamental, rompendo assim com o ciclo vicioso que se estabeleceu em que violência gera violência. Este contribui, portanto, de forma profilática, a danos inimagináveis no que tange ao comportamento e ao psiquismo de gerações futuras.

\section{Agradecimentos}

Agradecemos ao Fundo das Nações Unidas para a Infância (UNICEF) e ao Serviço Social de Comércio e à UFMA, na pessoa do Excelentíssimo Reitor Natalino Salgado Filho, pelo apoio e encorajamento, sem os quais a impressão e divulgação deste trabalho não teriam sido possíveis. À equipe que organizou as primeiras informações geradas pela pesquisa, as quais possibilitaram a criação de uma cartilha informativa sobre os principais Direitos da Criança na primeira infância; a todos os colegas professores e alunos que colaboraram com a execução e a redação final deste trabalho e aos nossos familiares, amigos e a todos que nos deram incentivo e motivação para a conclusão deste.

\section{Referências}

1. Bobbio N. A era dos direitos. Rio de Janeiro: Campus; 1992.

2. Campos GJB. Teoría de los derechos humanos. Cidade do México: Universidade Nacional Autônoma do México - Instituto de Investigações Jurídicas; 1989.

3. Scherer EA, Scherer ZA. A criança maltratada. Rev Latino-Am Enfermagem. 2000; 8 (4): 22-9.

4. Sauaia ASS. Violência doméstica contra a criança: uma epidemia ainda silenciosa. São Luís: Universidade Federal do Maranhão; 2010.

5. Bee H. A criança em desenvolvimento. 3. ed. São Paulo: Harbra; 1986.

6. Brito AMM, Zanetta DMT, Mendonça RCV, Barison SZP, Andrade VAG. Violência doméstica contra crianças e adolescentes: estudo de um programa de intervenção. Cienc Saúde Coletiva. 2005; 10(1): 143-9 [Internet] [acesso em 2012 Jan 18]. Disponível em: http://www.scielo.br/ scielo.php?script=sci_arttext\&pid=S1413-81232005000100021\&lng=pt http://dx.doi.org/10.1590/S1413-81232005000100021.

7. Boarati MC, Sei MB, Arruda SLS. Abuso sexual na infância: a vivência em um ambulatório de psicoterapia de crianças. Rev Bras Crescimento Desenvolv Hum. 2009; 19(3): 426-34.

8. Winnicott DW. Tudo começa em casa. Tradução: Paulo Sandler. São Paulo: Martins Fontes; 1999.

9. Hirigoyen M. Assédio moral: a violência perversa no cotidiano. $4^{a}$ Ed. Rio de Janeiro: Bertrand Brasil; 2000.

10. Oliveira IT. Psicoterapia Psicodinâmica Breve: dos precursores aos modelos atuais. Psicol Teor Prat. 1999; 1(2): 9-19.

11. Moreno M. Falemos de sentimento: a afetividade como tema transversal. São Paulo: Moderna; 1999. 